\title{
A CFD ANALYSIS OF THE OIL SQUEEZING POWER LOSSES OF A GEAR PAIR
}

\author{
FRANCO CONCLI \& CARLO GORLA \\ Politecnico di Milano, Mechanical Department, Milan, Italy.
}

\begin{abstract}
Efficiency is becoming more and more a main concern in the design of power transmissions and the demand for high efficiency gearboxes is continuously increasing. Also the more and more restrictive euro standards for the reduction of pollutant emissions from light vehicles impose to improve the efficiency of the engines but also of the gear transmissions. For this reason the resources dedicated to this goal are continuously increasing.

The first step to improve efficiency is to have appropriate models to compare different design solutions. Even if the efficiency of transmissions is quit high if compared with the efficiency of the engines and appropriate models to predict the power losses due to gear meshing, to bearings and to seals already exist, in order to have a further improvement, some aspects like the power losses related to the oil churning, oil squeezing and windage are still to be investigated. In previous papers the authors have investigated by means of computational fluid dynamic (CFD) analysis and experimental measurements the churning losses of planetary speed reducers (in which there is a relative motion between the "planets + planet carrier" and the lubricant).

Also the windage power losses have been studied by the authors in previous papers. This report is focused on the oil squeezing power losses. This kind of losses is associated with the compressionexpansion process by the meshing teeth. The contraction of the volume at the gear mesh implies an overpressure that induces a fluid flow primarily in the axial direction and this, for viscous fluids, means additional power losses and a decrease of the efficiency.

In this work this phenomena has been studied by means of some CFD simulations. The influence of some operating conditions like the lubricant properties, the rotational speed and the temperature has been studied.
\end{abstract}

Keywords: CFD, efficiency, gear, lubrication, oil squeezing, pocketing, power losses.

\section{INTRODUCTION}

As the fuel economy requirements and euro standards for the reduction of pollutant emissions are becoming more and more stringent, efficiency is becoming a main concern also in the design of power transmissions. Reducing fuel consumption and particulate emission levels through increasing efficiency has not only a strong impact on the economy and on the environment, but also on the reliability on the transmissions: reducing the power losses means reducing the heat generated and, therefore, the operating temperature of the transmission. A lower temperature is favorable for the system reliability. Furthermore a reduction of the generated heat allows to simplify the system avoiding, for example, complex cooling systems.

Source of losses in a gearbox can be classified, according to reference [1], into two main categories: (i) load dependent power losses and (ii) load independent power losses. The load dependent power losses are primarily related to a mechanical power loss due to sliding at the gear contact and in the bearings. The load independent power losses, in turn, are primarily related to viscous effects. These losses can be further subdivided into oil churning and windage losses that are the result of the interaction between the oil/air and the moving/rotating elements like gears and shafts, into pocketing/squeezing losses due to the pumping effect of 
the mating gears and into other viscous dissipations like those of the bearings. A comprehensive description of the subdivision of the losses as has been discussed by the authors in reference [2]. In order to predict these kinds of losses, literature provides many publications about the load dependent power losses, but only few works about load independent power losses. These works are primarily concerning the churning losses of ordinary gears, the spin power losses and the losses of the bearings. What is still needed are appropriate studies to predict the oil pumping/squeezing power losses. The works on this topic are few and simplified. Strasser [3] proposed a simplified fluid-dynamic model to predict the oil squeezing power losses in a spur gear pair. This model takes into account the variation of the gap between the teeth but it approximates the geometry. Seetharaman and Kahraman [4] proposed a physic-based fluid mechanics model to predict the spin power losses of a gear pair due to oil churning and windage. This model calculate the losses like the sum of the losses associated to the interactions of individual gears and the fluid and the power losses due to pumping of the oil at the gear mesh. To predict the oil pumping losses, Seetharaman and Kahraman developed an analytical model that take into account the variation of the volume of the gap between the teeth without simplifying the geometry like in the model proposed by Strasser. These models are able to give results in a very short time but they give only approximate results. For this reason, the authors have investigated this kind of losses by means of computational fluid dynamic(CFD) simulations that are able to correctly solve the velocity and the pressure fields without simplifications and, therefore, give more information about the phenomena [5-10]. In this study, the influence on this kind of losses of the oil temperature and of the rotational speed of the gears has been investigated.

\section{PROBLEM DESCRIPTION}

When a gear pair is mating, the volume of the cavity between the teeth is continuously changing. In the first steps of the engagement, the volume of the gap is reducing. This contraction of the volume implies an overpressure in the gap between the teeth. The lubricant is therefore squeezed out of the cavity. The oil flux takes place primarily in the axial direction thanks to the big lateral opened areas. While the gears are rotating, the minimum value for the volume is reached. From this point, the volume of the gap between the teeth starts a sudden expansion. This increase of the volume causes a negative pressure in the gap. Due to the negative pressure, the lubricant flows from the oil bath into the gap. This process is cyclic and, in general, there are multiple cavities that are squeezed together (Fig. 1).

Due to the viscous effects of the lubricant, this additional flow caused by the changes in the volume of the gap between the teeth implies additional losses. The value of this loss is strongly dependent from the lubrication type. In this first step of the research, a dip lubrication with $100 \%$ oil has been considered. This solution has two main advantages. The first one is that this condition is the simplest one: a partial immersion, in fact, complicates a lot the problem because it involves multiphase flows. The second one is that with a $100 \%$ lubricant immersion, the losses increase significantly and it is simpler to calculate them. The aim of this initial study was to understand the effect of the mating gears on the axial flows, so the full immersion lubrication was considered appropriate at this point of the research.

\section{GEOMETRY}

In order to study this kind of power loss, a standard spur gear pair has been used. Pinion and gear have the same dimensions. Table 1 summarized the main parameter of the gears. 

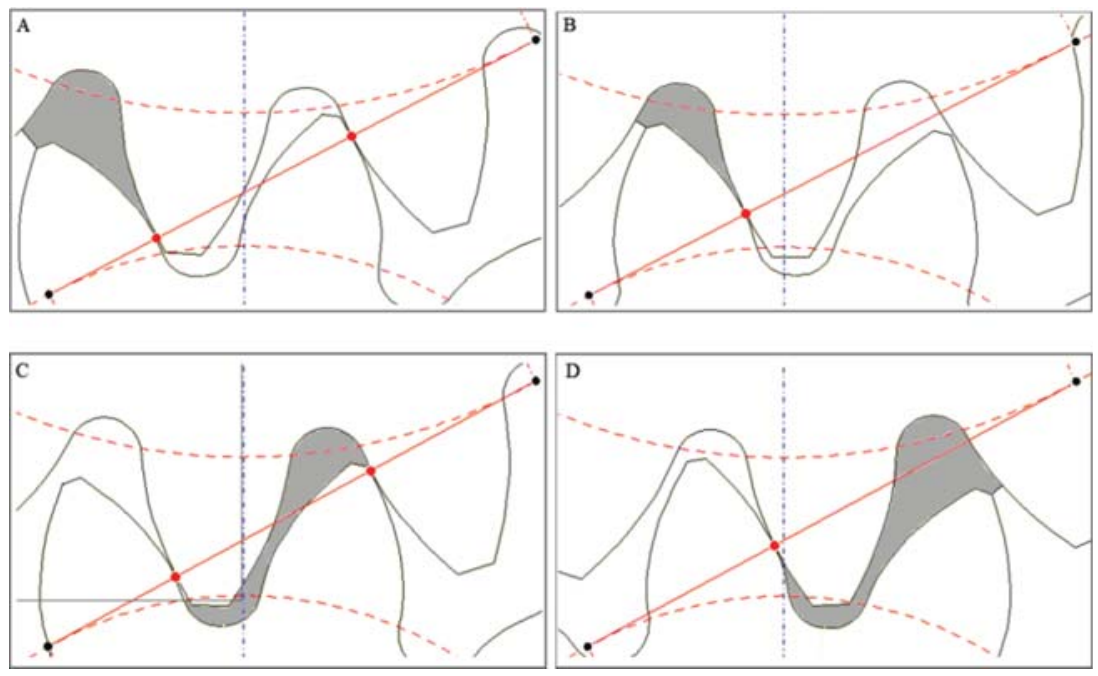

Figure 1: Change of the volume of the cavity during the engaging of the gears.

Table 1: geometrical parameters of the gear pair.

\begin{tabular}{llll}
\hline$\beta[\mathrm{rad}]$ & 0 & $\mathrm{r}[\mathrm{mm}]$ & 14.4 \\
$\beta^{\prime}[\mathrm{rad}]$ & 0 & $\mathrm{r}^{\prime}[\mathrm{mm}]$ & 14.45 \\
$\alpha^{\prime}[\mathrm{rad}]$ & 0.358452 & $\mathrm{Z}[/]$ & 36 \\
$\alpha[\mathrm{rad}]$ & 0.349066 & $\mathrm{rb}[\mathrm{mm}]$ & 13.5315 \\
$\mathrm{a}[\mathrm{mm}]$ & 28.8 & $\mathrm{~m}[\mathrm{~mm}]$ & 0.8 \\
$\mathrm{a}^{\prime}[\mathrm{mm}]$ & 28.9 & $\mathrm{~b}[\mathrm{~mm}]$ & 15.5 \\
$\mathrm{ra}[\mathrm{mm}]$ & 15.175 & $\beta \mathrm{b}[\mathrm{rad}]$ & 0 \\
ri $[\mathrm{mm}]$ & 13.4375 & &
\end{tabular}

From Table 1, it is possible to see that the considered gears are small, with a working diameter of $28.8 \mathrm{~mm}$ and a tooth high of about $1.74 \mathrm{~mm}$. As described in the following paragraphs, this kind of loss together with this kind of lubrication becomes important also for small gears like those adoptedhere.

The geometrical model adopted to study this phenomenon is shown in Fig. 2. Only five teeth pro gear have been modeled. The aim of this work, in fact, was to study in detail the behavior of the lubricant in the field of action. Furthermore, in order to reduce the amount of elements necessary for the discretization and thanks to the symmetry, only the half of the domain has been modeled. The domain has been discretized with a swept mesh. This meshing technique consists in creating a mesh on one side of the region, known as the source side, and then copying the nodes of that mesh, one element layer at a time, until the final side, known as the target side, is reached. The whole model has been discretized with triangular prisms. This kind of elements allows a larger aspect ratio compared with the tetrahedral cells in which it will invariably affect the skewness of the cell, which is undesirable as it may impede accuracy and 

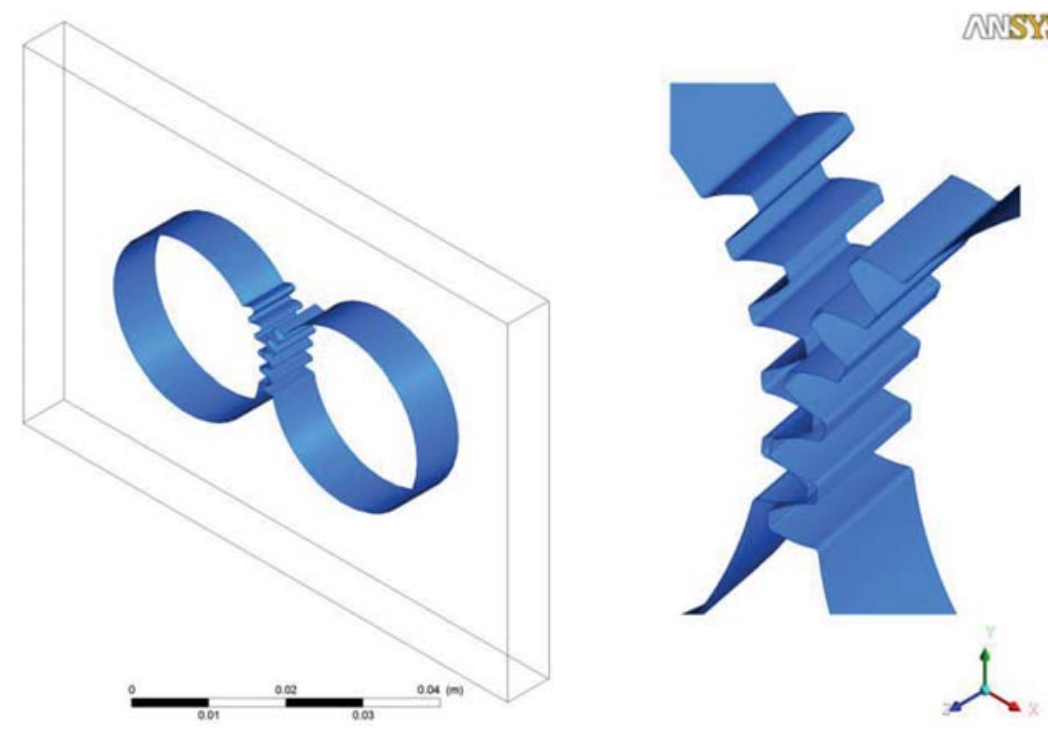

Figure 2: Geometrical model.

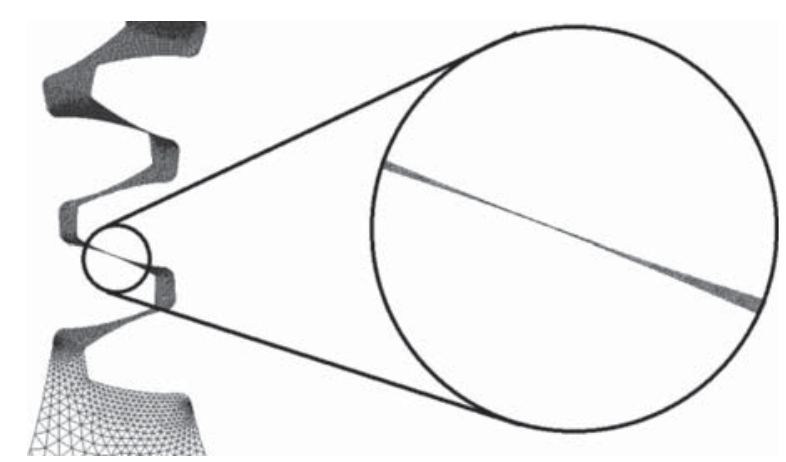

Figure 3: Details of the mesh.

convergence. Some mesh refinements have been performed in order to find the best compromise between the accuracy of the solution and the computational time. The real problem during the meshing operation is that it is necessary to model the thin oil film that rises between the mating teeth. The thickness of this film has a big influence on the results in terms of power loss. For this reason some geometries with different film thickness have been modeled. After a convergence study, the final model had a film thickness of about $0.5 \mu \mathrm{m}$. This means that the required mesh is extra fine. The smallest element has a length of about $0.2 \mu \mathrm{m}$ (Fig. 3).

\section{NUMERICAL MODEL}

To simulate the problem, a volume of fluid (VOF) approach has been used [11, 12]. This method is an Eulerian-Eulerian method characterized by a mesh that is (in this case) moving in a certain prescribed manner in order to accommodate the evolving shape of the interface. 
The governing equations are the conservation equations for mass and momentum. The energy equation is not activated in this simulations.

$$
\frac{\partial \mathrm{r}}{\partial \mathrm{t}}(\mathrm{r} \overrightarrow{\mathrm{v}})+\nabla \cdot(\rho \overrightarrow{\mathrm{v}} \overrightarrow{\mathrm{v}})=-\nabla \mathrm{P}+\nabla \cdot[\mu(\nabla \overrightarrow{\mathrm{v}}+\nabla \overrightarrow{\mathrm{v}} \mathrm{T})]+\rho \overrightarrow{\mathrm{g}}+\overrightarrow{\mathrm{F}}
$$

where $\rho$ is the density, $t$ is the time, $\vec{V}$ is the velocity vector, $P$ is the pressure, $\rho \vec{g}$ and $\overrightarrow{\mathrm{F}}$ are the gravitational body force and external body forces.

For compressible flows, the unknown are the velocity components and the density while the pressure is evaluated with a constitutive equation. For incompressible flows, the variables are the pressure and the velocity components. The solution of the system of equations for incompressible flows is accomplished by the fact that there are not equations where the pressure is explicitly defined. To calculate it, the continuity equation is substituted with an equation for the pressure; with some manipulation the pressure appears like unknown term in the momentum equation.

For this reasons, a Semi Implicit Method for Pressure-Linked Equations (SIMPLE) scheme has been adopted as suggested for flows in closed domains to solve the pressure-velocitycoupling [13]. This algorithm uses a relationship between velocity and pressure corrections to enforce mass conservation and to obtain the pressure field. The idea is that the pressure field must guarantee, at every time, the continuity equations. Is it therefore necessary to obtain a differential equation for the pressure unknown derived from continuity and momentum equations.

In this method, the pressure field is calculated as

$$
\mathrm{P}^{\mathrm{n}+1}=\mathrm{P} *+\mathrm{P}^{\prime}
$$

where $P^{*}$ is the estimated pressure guessed or obtained at the previous time step/iteration from the momentum equations and $P^{\prime}$ is the pressure correction

The velocity field is calculated as

$$
\vec{v}^{\mathrm{n}+1}=\vec{v}^{*}+\vec{v}
$$

where $\vec{v}^{*}$ is the estimated velocity calculated from the pressure $P^{*}$ and $\vec{v}^{\prime}$ is the velocity correction.

The gear surfaces have been set like no slip walls and the lateral sides of the domain as zero pressure to simulate the steady oil bath and as symmetry, respectively.

In order to reproduce the operating conditions, a rigid motion of the boundaries corresponding to the pinion and the gear has been applied by means of User Defined Functions (UDFs). With this boundary motion, it is possible to reproduce the real operating conditions in which gears are meshing. The time step for the transient analysis has been chosen as dynamic. This means that at every step, the new time increment depends on the velocity field.

$$
\Delta t=\frac{V_{\text {cell }, \text { min }}^{\frac{1}{2}}}{U}
$$

where $V_{\text {cell,min }}$ is the volume of the smallest cell in the computational domain and $U$ is the velocity scale of the problem. This allows to increase the calculations without the risk to lose the convergence. 
This boundary motion implies a deformation of the fluid domain. For this reason, it is necessary do update the mesh at every time step. In order to do that, a dynamic mesh model has been adopted: spring-based smoothing + remeshing. In this method, the edges between any two mesh nodes are idealized as a network of interconnected springs. The initial spacing of the edges before any boundary motion constitute the equilibrium state of the mesh. A displacement at a given boundary node will generate a force proportional to the displacement along all the springs connected to the node. Using Hook's law, the force on a mesh node can be written as

$$
\vec{F}_{i}=\sum_{j}^{n i} k_{i j}\left(\Delta \vec{x}_{j}-\Delta \vec{x}_{i}\right)
$$

where $\Delta \vec{x}_{j}$ and $\Delta \vec{x}_{i}$ are the displacements of nodeiand its neighbor $j, n_{j}$ is the number of the neighboring nodes connected to the node $i$ and $k_{i j}$ is the spring constant between node $i$ and its neighbor $j$. The spring constant for the edge connecting nodes $i$ and $j$ is defined as

$$
k_{i j}=\frac{1}{\sqrt{\left|\vec{x}_{j}-\vec{x}_{i}\right|}}
$$

At equilibrium, the net force on a node due to all the springs connected to the node must be zero. This condition results in an iterative equation such that

$$
\Delta \vec{x}_{i}^{m+1}=\frac{\sum_{j}^{n_{i}} k_{i j} \Delta \vec{x}_{j}^{m}}{\sum_{j}^{n_{i}} k_{i j}}
$$

Since displacements are known at the boundaries, Equation (8) is solved using a Jacobi sweep on all interior nodes. At convergence, the positions are updated such that

$$
\vec{x}_{i}^{n+1}=\vec{x}_{i}^{n}+\Delta \vec{x}_{i}^{m, \text { converged }}
$$

where $n+1$ and $n$ are used to denote the positions at the next time step and the current time step, respectively.

On zones with a triangular or tetrahedral mesh, the spring-based smoothing method is normally used. When the boundary displacement is large compared with the local cell sizes, the cell quality can deteriorate or the cells can become degenerate. This will invalidate the mesh and consequently, will lead to convergence problems when the solution is updated to the next time step. To circumvent this problem, it is possible to locally remesh some cells agglomerate that did not satisfy the skewness criteria or the maximum and minimum length allowed for the cells. In order to do that, a 2.5D remeshing method has been adopted.

\section{OPERATING CONDITIONS}

The purpose of the simulations is to calculate the power losses due to oil squeezing under different operating conditions.

In order to do that, the resistant torque on the driving shaft has been monitored. This resistant torque is calculated with a surface integral on the moving walls with respect to the gearbox axis and it is composed of two parts: the first given by the pressure and the second by the viscous effects. Starting from the resistant torque it is possible to calculate the power losses just by multiplying it by the rotational speed. The simulations have been computed with 
Table 2: Parameters for each simulation

\begin{tabular}{rccc}
\hline$\omega(\mathrm{rad} / \mathrm{s})$ & $\mathrm{T}\left({ }^{\circ} \mathrm{C}\right)$ & $\rho\left(\mathrm{kg} / \mathrm{m}^{3}\right)$ & $\eta(\mathrm{Pa} * \mathrm{~s})$ \\
\hline 52 & 40 & 1040.86 & 0.2289 \\
105 & 40 & 1040.86 & 0.2289 \\
157 & 40 & 1040.86 & 0.2289 \\
52 & 65 & 1021.61 & 0.1481 \\
105 & 65 & 1021.61 & 0.1481 \\
157 & 65 & 1021.61 & 0.1481 \\
52 & 90 & 1002.36 & 0.0702 \\
105 & 90 & 1002.36 & 0.0702 \\
157 & 90 & 1002.36 & 0.0702 \\
\hline
\end{tabular}

different combinations of operating temperature and rotational speed. In these simulations, the energy equation has not been activated. That means that the lubricant properties should be defined according to the chosen operating temperature and remain constant for the entire simulation. Three different rotational speeds and three different temperatures have been chosen. Combining the parameters, a $3 \times 3$ full factorial design has been followed.

Table 2 shows the combinations of parameters for each simulation. $T$ is the operating temperature in $\left[{ }^{\circ} \mathrm{C}\right], \omega$ is the rotational speed of the planet carrier in $[\mathrm{rad} / \mathrm{s}], \rho$ is the density in $\left[\mathrm{kg} / \mathrm{m}^{3}\right]$ and $\eta$ the dynamic viscosity in $\left[\mathrm{Pa}^{*} \mathrm{~s}\right]$. A commercial oil with this characteristics can be, for example, the Klubersynth GH 6-220 Synthetic Gear Oil.

\section{RESULTS}

Figure 4 shows the pressure field on the symmetry plane together with the pathlines. It is possible to appreciate that in the upper cavity the pressure is higher than in the oil bath. That is because this cavity is decreasing this volume. The lower cavity, in turn, shows a lower pressure depending on the fact that it is increasing this volume.

Figures 5 to 7 show the results in terms of power loss on the driving wheel for different operating conditions and for one cycle. The mating of the gear, in fact, is periodic and, therefore, also the resistant torque necessary to squeeze the oil has a periodic trend.

From the diagrams, it can be seen that, as expected, the resistant torque decreases with temperature while it increases with rotational speed.

Figure $6 \mathrm{c}$ shows the case in which the temperature is the highest $\left(90^{\circ} \mathrm{C}\right)$ while the rotational speed is the lowest $(52 \mathrm{rad} / \mathrm{s})$. In these conditions also, with a $100 \%$ dip in lubrication, the losses are less than $1 \mathrm{~W}$ and can be neglected in the computation of the total efficiency of the gearbox.

Figure 6a shows the results for the same rotational speed but for the lowest temperature $\left(40^{\circ} \mathrm{C}\right)$. In this case the losses increase significantly but remain limited to about $2 \mathrm{~W}$.

A more sudden increment is related to an increment of the rotational speed. Figure 7 a can be compared with Fig. 6a. A doubling of the rotational speed from 52 to $105 \mathrm{rad} / \mathrm{s}$ with the same temperature of $40^{\circ} \mathrm{C}$ induces an increase in the losses up to four times. An additional increase of $50 \%$ of the rotational speed up to $157 \mathrm{rad} / \mathrm{s}$ causes a sudden growth of the loss that rises to $21 \mathrm{~W}$. Even if $21 \mathrm{~W}$ can be just a little percentage of the total losses of a geared transmission, this cannot be neglected. 

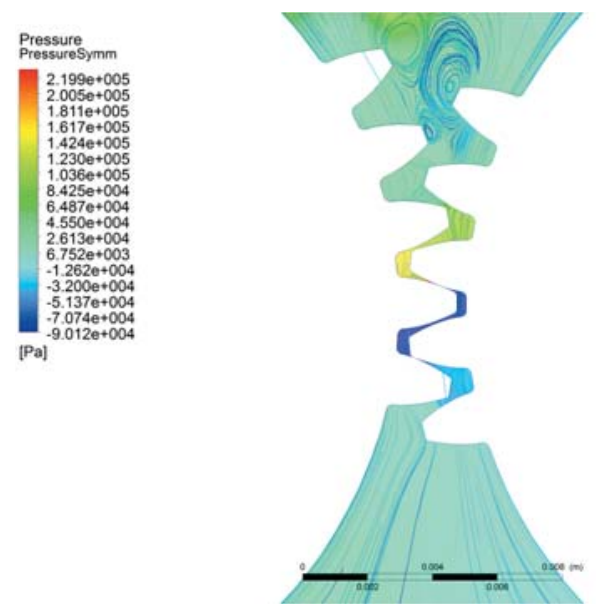

ANSYS

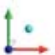

Figure 4: Contour plot of the pressure field in the symmetry plane and pathlines according to the velocity.

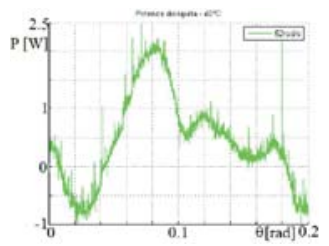

(a)

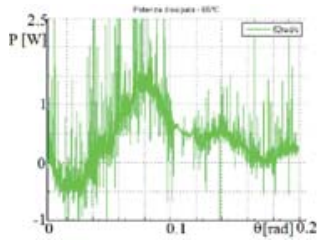

(b)

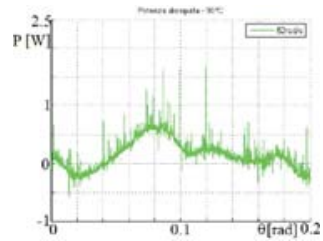

(c)

Figure 5: Power losses on the driving shaft; (a) $40^{\circ} \mathrm{C}-52 \mathrm{rad} / \mathrm{s}$; (b) $65^{\circ} \mathrm{C}-52 \mathrm{rad} / \mathrm{s}$; (c) $90^{\circ} \mathrm{C}$ $-52 \mathrm{rad} / \mathrm{s}$

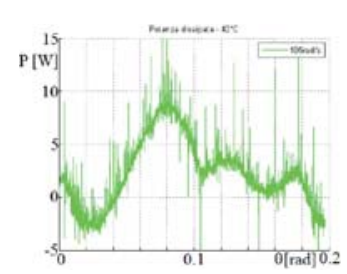

(a)

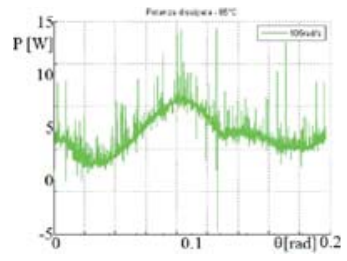

(b)

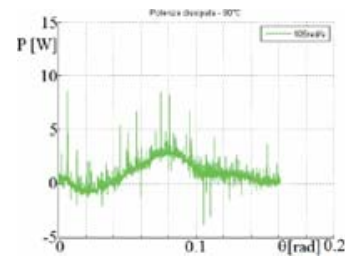

(c)

Figure 6: Power losses on the driving shaft; (a) $40^{\circ} \mathrm{C}-105 \mathrm{rad} / \mathrm{s}$; (b) $65^{\circ} \mathrm{C}-105 \mathrm{rad} / \mathrm{s}$; (c) $90^{\circ} \mathrm{C}$ $-105 \mathrm{rad} / \mathrm{s}$

The previous diagrams also show that the trend of the losses versus the angle of rotation in always the same. Figure 8 shows in detail those trends.

Figure 8 shows the power losses along the contact path. In the position 1 the first teeth pair $(1 s+2 s)$, as shown in Fig. 9a, is already engaged. The second teeth pair $(2 s+3 s)$ is starting the contact. In position 2 of Fig. 8, the first teeth pair ended the contact (Fig. 9b).

Between 1 and 2, the mating teeth pairs are therefore 2 . In the position 3, another teeth pair $(3 s+4 d)$ starts the contact (Fig. 9c) while the second teeth pair $(2 s+3 s)$ is already engaged. Like in position 2 , in position 4 a teeth pair $(2 s+3 s)$ ended the contact (Fig. 9d). 


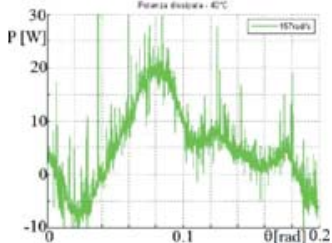

(a)

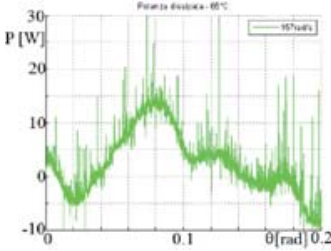

(b)

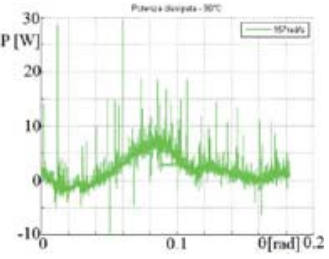

(c)

Figure 7: Power losses on the driving shaft; (a) $40^{\circ} \mathrm{C}-157 \mathrm{rad} / \mathrm{s}$; (b) $65^{\circ} \mathrm{C}-157 \mathrm{rad} / \mathrm{s}$; (c) $90^{\circ} \mathrm{C}$ $-157 \mathrm{rad} / \mathrm{s}$

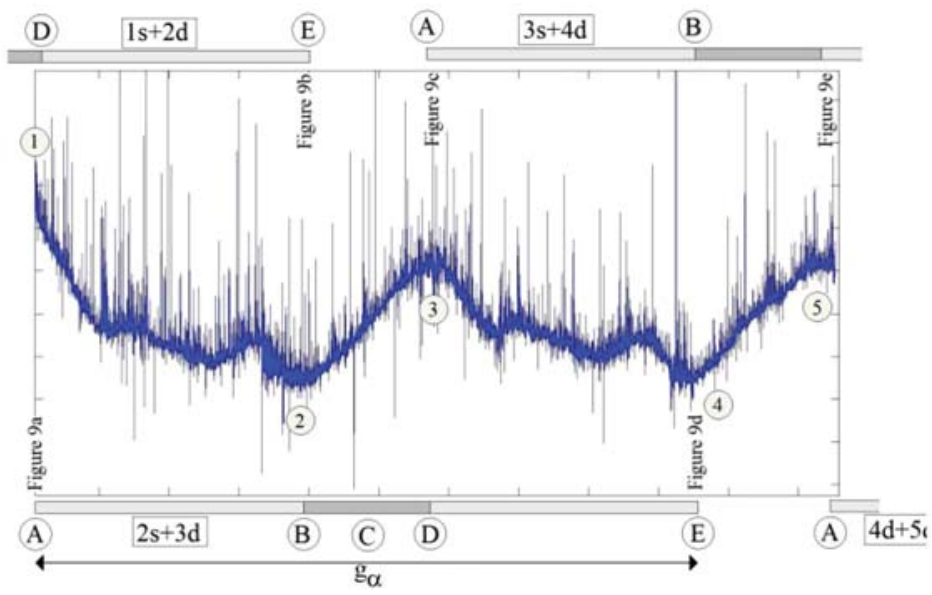

Figure 8: Power losses versus length of contact.

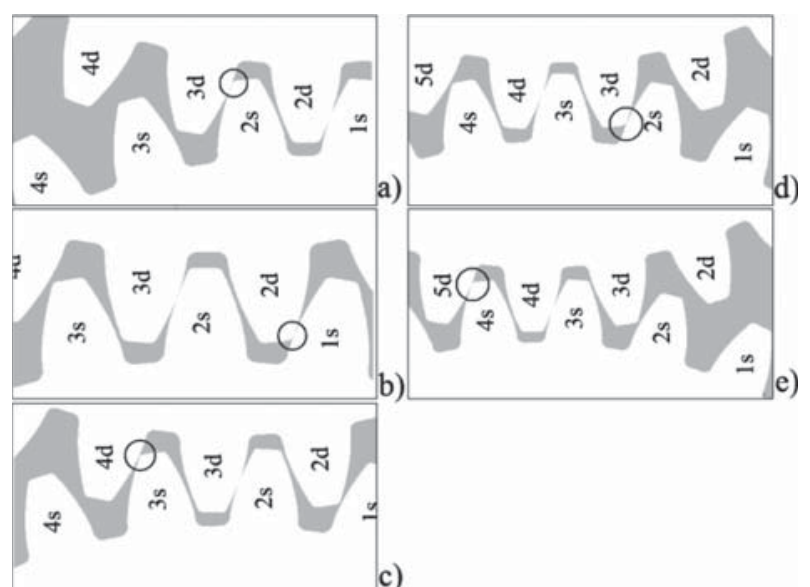

Figure 9: Different engaging steps. 
From this position to position 5, the engaged teeth pair is again only one, like between position 2 and position 3. Finally, in position 5, like in position 3, a teeth pair starts the contact while another teeth pair is already engaged (Fig. 9e).

\section{CONCLUSIONS}

As reliable models to accurately predict the oil squeezing losses at the gear meshing are still not available, a CFD model has been applied in order to predict this important component of losses.

The numerical simulations allowed to describe the amount of loss due to pocketing along the contact path. This can be very helpful for the understanding of the phenomena. Furthermore the simulations show the influence on the losses of different parameters: this kind of loss increases, as expected, with the rotational speed and decreases with temperature. The results show that for low regimes and high temperature, this kind of loss are particularly low and can be neglected in the computation of the efficiency of the transmission. The decrease of the temperature has less influence on the losses than the increase of the rotational speed. In order to cut in half the losses an increase of $125 \%$ in the temperature (from $40^{\circ} \mathrm{C}$ to $90^{\circ} \mathrm{C}$ ) is necessary while a decrease of $50 \%$ of the rotational speed (from 157 to $105 \mathrm{rpm}$ ) is enough.

The results also show that the increase of the losses from the best case $\left(90^{\circ} \mathrm{C}\right.$ and $\left.57 \mathrm{rad} / \mathrm{s}\right)$ to the worst case $\left(40^{\circ} \mathrm{C}\right.$ and $\left.157 \mathrm{rad} / \mathrm{s}\right)$ (temperature increase of $125 \%$ and rotational speed increase of $150 \%$ ) can be of about $2000 \%$ (from less than $1 \mathrm{~W}$ up to about $20 \mathrm{~W}$ ). This fact suggests that also this kind of losses have to be taken into account in order to obtain a good prediction of the efficiency of a geared transmission.

Future work will be addressed to the study of other geometries and other kinds of lubrications.

\section{REFERENCES}

[1] Niemann, G. \& Winter, H., Maschinenelemente - Band 2: Getriebeallgemein, Zahnradgetriebe -Grundlagen, Stirnradgetriebe - 2. Auflage, Springer: Berlin, 2003.

[2] Gorla, C., Concli, F., Stahl, K., Hohn, B.-R., Michaelis, K., Schultheift, H. \& Stemplinger, J.-P., CFD simulations of splash losses of a gearbox. Advances in Tribology, 2012, Article Id: 616923, 2012.

[3] Strasser, D., Einfluss des Zahnflanken- und Zahnkopfspieles auf die Leerlaufverlustleistung von Zahnradgetrieben - Dissertation zurErlangung des Grades Doktor-Ingenieur, Bochum, 2005.

[4] Seetharaman, S. \& Kahraman, A., Load-independent spin power losses of a spur gear pair: model formulation. Journal of Tribology, 131(2), p. 11, 2009.

[5] Concli, F. \& Gorla, C., CFD simulations of windage losses of a gearbox, Engine SOFT International Conference 2012, Conference Proceedings, 2011.

[6] Concli, F., Gorla, C., Arigoni, R., Cognigni, E. \& Musolesi, M., Planetary speed reducers: efficiency, backlash, stiffness. International Conference on Gears, Munich, 2010.

[7] Concli, F. \& Gorla, C., Computational and experimental analysis of the churning power losses in an industrial planetary speed reducers, WIT Transactions on Engineering Sciences - Advances in Fluid Mechanics IX Vol. 74, pp. 287-298, 2012.

[8] Concli, F. \& Gorla, C., Influence of lubricant temperature, lubricant level and rotational speed on the churning power losses in an industrial planetary speed reducer: computational and experimental study. International Journal of Computational Methods and Experimental Measurements, 1(4), Wessex Institute of Technology, 2013 
[9] Concli, F. \& Gorla, C., Churning power losses in planetary speed reducer: computational and experimental analysis. Enginesoft international conference 2011 - Ansys Italian conference 2011, Verona 2011.

[10] Concli, F. \& Gorla, C., Analysis of the oil squeezing power losses of a spur gear pair by mean of CFD simulations, ESDA International Conference 2012, Nantes 201.

[11] Patankar, S.V., Numerical Heat Transfer and Fluid Flow. Taylor \& Francis: USA, 1980.

[12] Versteeg, H.K. \& Malalasekera, W., An Introduction to Computational Fluid Dynamics The Finite Volume Method. Longman Group: London, 1995.

[13] Comini, G., Fondamenti di termofluidodinamicacomputazionale, SGEditoriali, Padova, 2004. 